\title{
Molecular detection of Strongyloides sp. in Australian Thoroughbred foals
}

\author{
Ghazanfar Abbas ${ }^{1}$, Abdul Ghafar ${ }^{1}$, Anson V. Koehler ${ }^{1}$, Jenni Bauquier ${ }^{1}$, Edwina J. A. Wilkes², Caroline Jacobson³ \\ Anne Beasley ${ }^{4}$, John Hurley ${ }^{5}$, Lucy Cudmore ${ }^{6}$, Peter Carrigan ${ }^{6}$, Brett Tennent-Brown ${ }^{1}$, Charles El-Hage ${ }^{1}$, \\ Martin K. Nielsen ${ }^{7}$, Charles G. Gauci ${ }^{1}$, Kristopher J. Hughes ${ }^{2}$, lan Beveridge ${ }^{1}$ and Abdul Jabbar ${ }^{1 *}$ (D)
}

\begin{abstract}
Background: Strongyloides westeri is found in the small intestine of young horses, mainly in foals up to about 16 weeks of age. The main source of infection for foals is through transmammary transmission, and foals can develop acute diarrhoea, weakness, dermatitis and respiratory signs. The epidemiology of S. westeri in Australia is largely unknown. Further, molecular techniques have never been employed for detection of $S$. westeri in horses. This pilot study aimed to assess the utility of a molecular phylogenetic method for the detection of $S$. westeri in the faeces of foals.
\end{abstract}

Methods: Faecal samples were collected from a foal of less than 2 months of age, and eggs of Strongyloides sp. were detected using the modified McMaster technique. DNA was extracted from purified eggs, and a partial fragment of the small subunit of the nuclear ribosomal DNA (18S) was characterised using polymerase chain reaction, DNA sequencing and phylogenetic methods.

Results: Microscopic examination of faeces revealed small ellipsoidal eggs typical of Strongyloides sp. The $18 \mathrm{~S}$ sequence generated by PCR in this study revealed $98.4 \%$ identity with that of a reference sequence of $S$. westeri available from GenBank. Phylogenetic analyses revealed a polyphyletic clustering of $S$. westeri sequences.

Conclusion: This is the first study reporting the detection of DNA of Strongyloides sp. in faeces of a foal using a molecular phylogenetic approach targeting the variable region of $18 \mathrm{~S}$ rDNA. It is anticipated that this study will allow future molecular epidemiological studies on S. westeri in horses.

Keywords: Australian Thoroughbred horses, Strongyloides sp., Genetic characterisation, Sanger sequencing

\section{Background}

Strongyloides (threadworms) is a genus of gastrointestinal nematodes of vertebrates comprising more than 50 species [1]. Strongyloides westeri infects horses, mainly young foals up to 16 weeks of age, and it is the first nematode to reach patency in the small intestine of foals [2]. A remarkable feature of the $S$. westeri life cycle is the ability to alternate between a sexual free-living phase and a

\footnotetext{
*Correspondence: jabbara@unimelb.edu.au

${ }^{1}$ Melbourne Veterinary School, The University of Melbourne, Werribee, Australia
}

Full list of author information is available at the end of the article parasitic phase consisting only of adult females shedding eggs by parthenogenesis [2].

Foals may become infected with parasitic third-stage larvae (L3s) of S. westeri through transmammary, percutaneous and oral routes. However, the transmammary route is considered the main source of transmission where L3s are transmitted from mare to foal via milk, which starts as early as day 4 postpartum and may continue up to several weeks [2-4]. The prepatent period via transmammary transmission is slightly shorter (8-12 days) than those of percutaneous and oral routes (10-14 days) because larvae migrating via the mammary original author(s) and the source, provide a link to the Creative Commons licence, and indicate if changes were made. The images or other third party material in this article are included in the article's Creative Commons licence, unless indicated otherwise in a credit line to the material. If material is not included in the article's Creative Commons licence and your intended use is not permitted by statutory regulation or exceeds the permitted use, you will need to obtain permission directly from the copyright holder. To view a copy of this licence, visit http://creativecommons.org/licenses/by/4.0/. The Creative Commons Public Domain Dedication waiver (http://creativeco mmons.org/publicdomain/zero/1.0/) applies to the data made available in this article, unless otherwise stated in a credit line to the data. 
glands are at an advanced stage of development and appear to not undergo somatic migration in the foals. [5].

Depending upon the route of transmission and parasite burden, foals can develop acute diarrhoea, weakness, dermatitis and respiratory signs $[3,6]$. Episodes of frenzied foal behaviour are characterised by skin irritation, extreme discomfort and dermatitis due to infective L3s [7]. A significant association between high faecal S. westeri egg counts and diarrhoea in younger foals has been reported [8].

The modified McMaster faecal egg count (FEC) technique has been the most commonly used method for the diagnosis of $S$. westeri in horses. Some studies have reported total worm counts based on recovery of adult worms and larvae at necropsy [2, 9-13]. Although sensitive and advanced molecular tools have been used for the detection of other Strongyloides spp. from humans and animals [14-18], one reason that very little is known about the molecular epidemiology of $S$. westeri is that such tools have never been employed for its detection in horses. Additionally, data on the genetic diversity within this species are scarce, as only a single partial sequence of the small subunit of nuclear ribosomal DNA (18S) is available in the public database, GenBank [19]. Therefore, this study aimed to assess the utility of a molecular phylogenetic method for the detection of $S$. westeri in the faeces of foals by amplifying the partial $18 \mathrm{~S}$ sequence.

While conducting a national survey on the gastrointestinal nematodes of Thoroughbred horses in Australia, we identified faecal samples (collected at a monthly interval) of a foal positive for Strongyloides sp. eggs during routine screening. These samples came from a Thoroughbred farm in the Hunter Valley, New South Wales, Australia, which has warm and temperate climatic conditions, with an average annual rainfall of $630 \mathrm{~mm}$. The farm had a total of 335 horses, including 86 resident mares, 73 yearlings and 60 foals. All young horses were dewormed routinely every 7-8 weeks, while the adult horses receive anthelmintics preventatively every 4 to 6 months. Currently, no pre-foaling deworming of mares is performed on this farm, and mares are dewormed using a combination of moxidectin and praziquantel (Equest ${ }^{\circledR}$ Plus Tape, Zoetis Pty. Ltd., Australia) 10 days after foaling, whereas foals receive a combination of oxfendazole and pyrantel (Strategy-T ${ }^{\circledR}$, Virbac Pty. Ltd., Australia) at 2 months of age.

Following the detection of Strongyloides sp. eggs, fresh faecal samples were collected from a foal at the age of 23 and 52 days and shipped overnight to the laboratory. Each faecal sample was tested using the modified McMaster technique [20]. Briefly, four grams of faeces were mixed with four $\mathrm{ml}$ of water. The faecal slurry was then mixed with $52 \mathrm{ml}$ of sucrose (specific gravity 1.27, www.csrsugar.com.au) solution and homogenised using a spatula. Following homogenisation, a sample was pipetted into two chambers of a Whitlock egg counting slide (www.whitlock.com.au). After 10 min, eggs were counted under a compound light microscope. The minimum detection limit using this method was 15 eggs per gram (epg) of faeces.

Five $\mathrm{ml}$ of the remaining suspension containing nematode eggs and saturated sugar solution from the sample were transferred to a 50-ml Falcon tube for recovery and concentration of nematodes eggs as previously described [21]. The washed eggs in each sample were transferred to a microcentrifuge tube and stored at $-20^{\circ} \mathrm{C}$ until further use. Following thawing, $250 \mu \mathrm{l}$ of the concentrated egg solution were used to extract and isolate DNA using the DNeasy PowerSoil extraction kit (Qiagen, Hilden, Germany) according to the manufacturer's protocol. DNA samples were stored at $-20{ }^{\circ} \mathrm{C}$ until further molecular analysis.

A molecular phylogenetic method was used for the unequivocal identification of Strongyloides sp. eggs present in foal faeces from the farm under investigation. The partial $5^{\prime}$ variable region (392 base pairs) of the 18S DNA was amplified using polymerase chain reaction (PCR) in a T100 thermal cycler (BioRad, Hercules, CA, USA) using SSUA_F (5'-AAAGATTAAGCCATGCATG-3') and SSU22_R (5'-GCCTGCTGCCTTCCTTGGA-3') primers as previously described by Dorris et al. [19]. PCR amplifications (initial denaturation at $95^{\circ} \mathrm{C}$ for 5 min followed by 35 cycles of denaturation at $95^{\circ} \mathrm{C}$ for $30 \mathrm{~s}$, annealing at $60{ }^{\circ} \mathrm{C}$ for $20 \mathrm{~s}$ and extension at $72{ }^{\circ} \mathrm{C}$ for $30 \mathrm{~s}$, and the final extension at $72{ }^{\circ} \mathrm{C}$ for $5 \mathrm{~min}$ ) were carried out in a final reaction volume of $25 \mu$ l containing $3.12 \mathrm{mM}$ of each deoxynucleotide triphosphate (dNTP), $12.5 \mathrm{pmol}$ of each primer, $10 \mathrm{mM}$ Tris- $\mathrm{HCl}(\mathrm{pH} 8.4), 75 \mathrm{mM} \mathrm{MgCl} 2$ and $0.62 \mathrm{U}$ of GoTaq Flexi DNA polymerase (Promega, Madison, WI, USA). Known positive (genomic DNA of Strongyloides stercoralis) and negative (Milli-Q $\mathrm{H}_{2} \mathrm{O}$ ) controls were included in each PCR run. Aliquots $(5 \mu \mathrm{L})$ of individual amplicons were analysed on $1.5 \%(\mathrm{w} / \mathrm{v})$ agarose gel in Tris-borate-EDTA buffer stained with GelRed (Biotium) and visualised using a GelDoc system (BioRad, Hercules, CA, USA).

Amplicons were purified using shrimp alkaline phosphate and exonuclease I (Thermo Fisher Scientific, Australia) before automated Sanger DNA sequencing using the PCR primers in separate reactions. The quality of the sequences was assessed in the Geneious Prime 2021.1.1 software (Biomatters Ltd., Auckland, New Zealand; www. geneious.com). The DNA sequence determined herein has been submitted to the GenBank database under the accession number MZ749458. Published 18S sequences of Strongyloides spp. from humans and domestic and wild 
animals were obtained from GenBank and were aligned with our 18S sequence using MUSCLE in Mesquite v.3.61 (http://www.mesquiteproject.org) using default settings and were trimmed to uniform lengths of $306 \mathrm{bp}$. The evolutionary model $(\mathrm{T} 92+\mathrm{G})$ of the DNA sequence data set was determined using the Akaike and the Bayesian information criteria (AIC and BIC) tests in jModelTest v.2.1.5 [22]. Neighbour-joining (NJ) trees were constructed using MEGA 10.2.5 [23], and Bayesian inference (BI) trees were built using MrBayes software [24]. The NJ trees were constructed with 10,000 bootstrap replicates using the Tamura-Nei distance method. The BI analysis was run for 20,000,000 generations (ngen $=20,000,000$ ) to calculate posterior probabilities (pp), with two runs, with every 200th tree saved (samplefreq $=200$ ). The $18 \mathrm{~S}$ rDNA sequence of Halicephalobus gingivalis was used as an outgroup. Tree topology was checked for consensus between $\mathrm{NJ}$ and $\mathrm{BI}$ analyses.

Microscopic examination revealed small ellipsoidal nematode eggs ranging between $40-50 \times 50-60 \mu \mathrm{m}$, and FECs were 90 and $750 \mathrm{epg}$ in samples collected at the age of 29 and 52 days, respectively. PCR amplicons revealed an expected size band ( $400 \mathrm{bp})$ on $1.5 \%$ agarose gel, and the partial 18S DNA sequence (363 bp) obtained herein (GenBank accession no. MZ749458) had a $98.4 \%$ similarity with that of a reference sequence identified from $S$. westeri in the USA (GenBank accession no. AJ417032) [19]. Pairwise comparison of our sequence with selected $18 \mathrm{~S}$ reference sequences of various Strongyloides spp. showed percentage differences ranging between 1.6 and 5.7\% (Table 1). An alignment of the $18 \mathrm{~S}$ reference sequences of Strongyloides spp. together with our sequence revealed four nucleotide differences with $S$. westeri linked to transition $(\mathrm{C} \leftrightarrow \mathrm{T}$; position 40) or transversions ( $\mathrm{A} \leftrightarrow \mathrm{T}$; positions 41,82 , and 88) (see Additional file 1: Figure S1). Genetic relationships assessed utilising $\mathrm{NJ}$ and $\mathrm{BI}$ methods produced similar topologies; therefore, only the BI tree is presented here (Fig. 1). The phylogenetic analyses revealed that the $18 \mathrm{~S}$ sequence of Strongyloides sp. determined herein grouped outside all other Strongyloides spp. included in this study $(\mathrm{pp}=0.84)$. However, our $18 \mathrm{~S}$ sequence grouped between those of the only available reference sequence of $S$. westeri (GenBank AJ417032, fixed material from horse) and Parastrongyloides trichosuri (AJ417024, fresh material from the Australian brushtail possum) [19].

This study describes the morphology of eggs and molecular detection of Strongyloides sp. in an Australian Thoroughbred foal. It reports the first PCR-based detection of DNA of Strongyloides sp. from eggs purified from faecal samples of a foal, which paves the way for future molecular epidemiological studies on $S$. westeri in horses. Previously, only one study has reported $S$. westeri in Australian horses, based on the examination of adult worms collected at necropsy [13].

Strongyloides westeri is believed to infect foals up to 4 months of age, and the foal tested in the present study was less than 2 months [2]. The route of infection of $S$. westeri found in this study is likely to be transmammary, as the mare did not receive a pre-foaling anthelmintic treatment, although we have not demonstrated the presence of larvae in the milk. Third-stage larvae of $S$. westeri have been reported in the milk of mares from the fourth day after foaling up to day 47 postpartum $[3,4]$. Recently, a study demonstrated the presence of $S$. westeri in foals of up to 8 months of age, suggesting that infection could last longer in foals, weanlings, or yearlings, but the number of parasites declines as animals get older [12].

The prevalence for $S$. westeri in Australian horses is not well studied and could be higher than previously thought. During the first half of the twentieth century, $S$. westeri was highly prevalent in foals in central Kentucky and other parts of the world. However, from the midtwentieth to early twenty-first centuries, the prevalence of this parasite declined markedly ( $<10 \%$ prevalence of $S$. westeri in the surveyed horses) due to the use of highly effective anthelmintics, including benzimidazoles and macrocyclic lactones $[9,13]$. However, $S$. westeri prevalence in foals from the same sampling area in Kentucky, USA, increased from $<6 \%$ (late 1900s and early 2000s) to $30 \%$ (2014) [11], probably due to the decreased use of ivermectin in foals because of the development of anthelmintic resistance in Parascaris spp. in horses [10]. In another study, lower prevalence and sporadic occurrence of $S$. westeri in foals from New Zealand was reported [25]. It is possible that the recommended shift away from frequent deworming of foals with macrocyclic lactones (due to the development of resistance in ascarid worms) may lead to an increase in $S$. westeri prevalence. A molecular phylogenetic technique, such as that described herein, would be an important tool for assessing the occurrence of $S$. westeri in horses worldwide.

To date, all studies of $S$. westeri have used FEC and larval or adult morphology following coproculture for the identification of parasites, which both have lower sensitivity than PCR $[26,27]$. Further, the identification of Strongyloides spp. solely on the basis of morphological characteristics of different stages of parasites can be difficult [17]. More than 50 species of Strongyloides have been reported from various hosts [1], and the list is expanding, as recently a new species $S$. vituli of cattle was separated from S. papillosus, although previously both were included under a single species name [16, 28].

Comparison of the partial $18 \mathrm{~S}$ sequence of Strongyloides sp. determined in the current study and that of S. westeri (GenBank AJ417032) from the USA revealed 


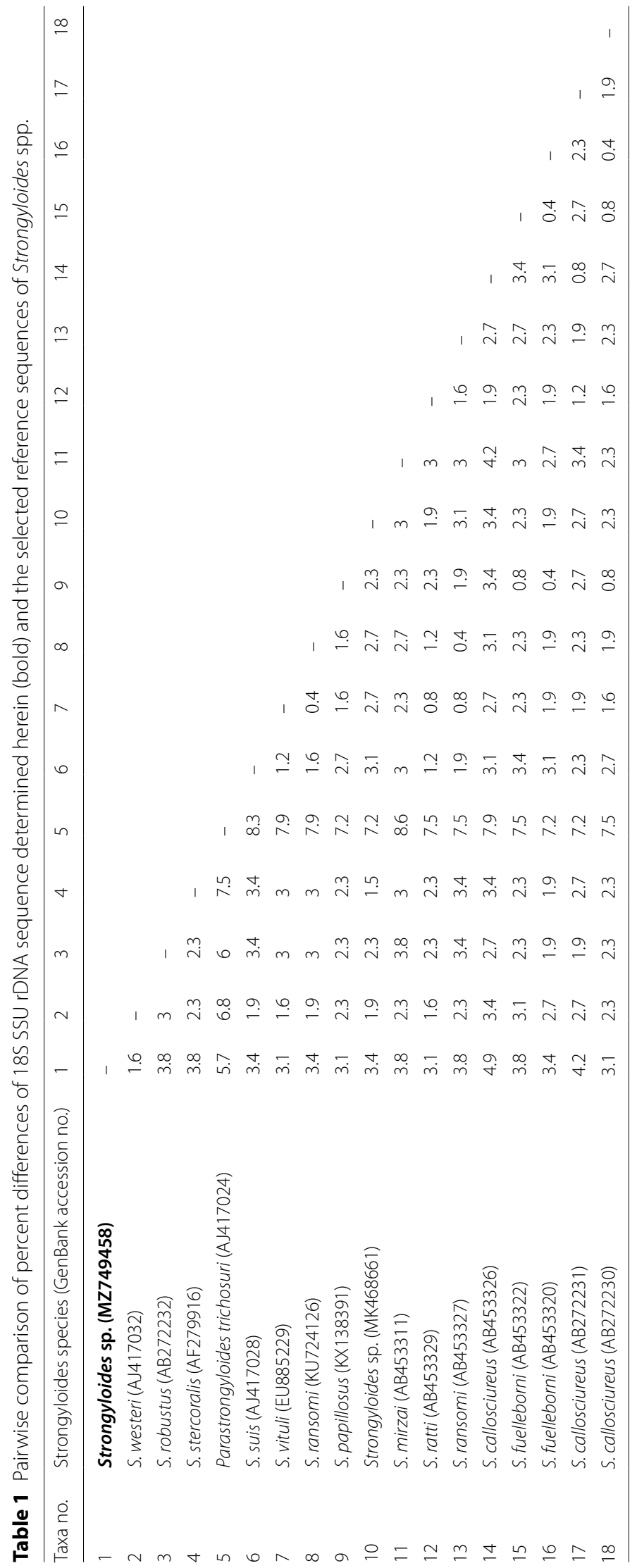




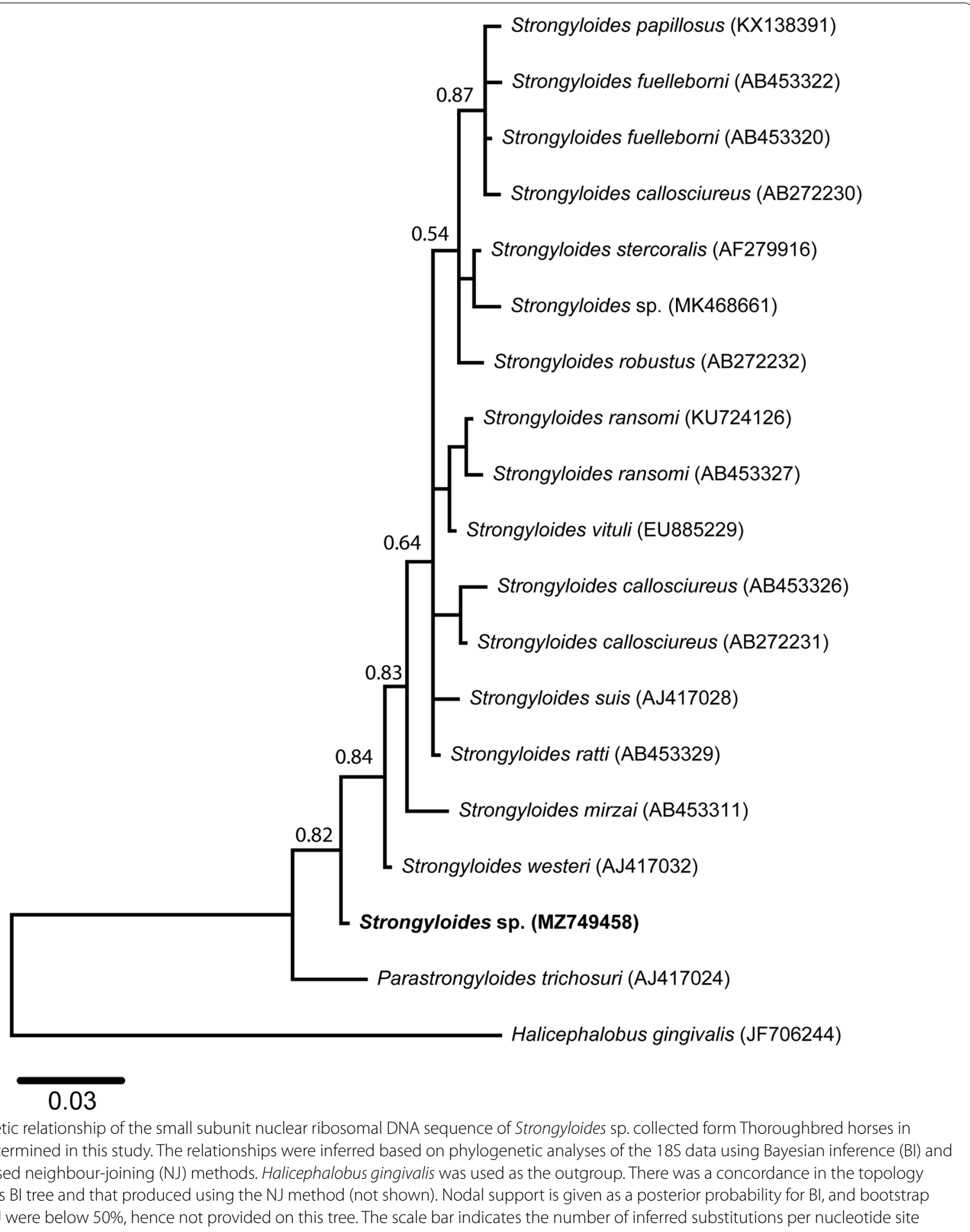

a difference of four base pairs over a sequence length of $270 \mathrm{bp}$ (see Additional file 1: Figure S1) which is an unlikely finding in the same species given the high degree of conservation of $18 \mathrm{~S}$ in the genus Strongyloides [19]. This difference could be due to (i) a rare polymorphism (variation at a single position in a DNA sequence among individuals) among different copies of SSU loci within genomes of Strongyloides spp. as well as other nematodes $[19,29]$ and/or (ii) the difference in the quality of DNA used as a template in PCRs. For example, we extracted 
genomic DNA from eggs purified from freshly collected faecal samples from a foal, while Dorris et al. [19] extracted DNA from a formalin-fixed specimen of $S$. westeri. Previously, a few studies reported a difference of $10 \%$ in DNA sequences from formalin-fixed specimens versus fresh specimens of the same species [30]. Dorris et al. [19] also proposed the possibility of a non-random effect on DNA due to formalin fixation that could cause a repeatable change in subsequent sequences. Similarly, Eberhardt et al. [28] found a difference of four base pairs between $18 \mathrm{~S}$ sequences of S. papillosus and those of the same species previously published by Dorris et al. [19], and it was hypothesised that these differences could possibly be due to molecular synapomorphy (characters shared by a group of taxa due to their inheritance from a common ancestor) which exists in the 330-bp $18 \mathrm{~S}$ sequence used for phylogenetic analyses by Dorris et al. [19].

In the present study, phylogenetic analyses revealed that the two possible $S$. westeri sequences did not group together (see Fig. 1) which could potentially be due to soft polytomy (insufficient phylogenetic information due to short sequence length) or sequences belonging to separate species. Previously, Dorris et al. [19] compared the SSU sequences of 12 species of Strongyloides and related nematodes and found that the $S$. westeri sequence showed a separate basal polytomy from the rest of the closely related species in Strongyloides that branched together in two clades. Previously, S. stercoralis was considered as a single species known to infect dogs; however, based on the analyses of the hypervariable region of $18 \mathrm{~S}$ and cytochrome $c$ oxidase subunit I mitochondrial DNA, two genetically different variants of $S$. stercoralis were identified which can infect dogs and humans [31]. Likewise, S. fuelleborni known to infect humans and other primates, has now been divided into two subspecies, $S$. fuelleborni fuelleborni and S. fuelleborni kellyi, on the basis of molecular evidence [32]. Similar diversification is observed in S. callosciureus, a species that infects a variety of squirrels worldwide [17]. It has been proposed that the species diversity in Strongyloides genus may be associated with the geographical location and evolutionary history of the hosts [17], including horses, which requires further investigation.

\section{Conclusion}

This is the first study reporting the detection of DNA of Strongyloides sp. in the faecal samples of a Thoroughbred foal using a molecular phylogenetic approach targeting the variable region of $18 \mathrm{~S}$ rDNA. Phylogenetic analyses revealed a basal polytomy of the sequence determined here, and it grouped separately along with the only reference sequence of $S$. westeri. We hypothesise that this genetic variation could be due to (i) the genetic diversity within $18 \mathrm{~S}$ rDNA of $S$. westeri, (ii) a polymorphism, (iii) sequencing errors in the previously reported sequence from the formalin-fixed specimen of S. westeri or (iv) the existence of cryptic or subspecies. However, these hypotheses warrant further molecular analyses of a range of DNA samples extracted from various developmental stages of the $S$. westeri collected from different locations globally using multiple molecular markers. The use of molecular phylogenetic tools offers opportunity for improved diagnosis and epidemiological studies of $S$. westeri in horses worldwide.

\section{Supplementary Information}

The online version contains supplementary material available at https://doi. org/10.1186/s13071-021-04966-1.

Additional file 1: Figure S1. Alignment of the small subunit nuclear ribosomal DNA (18S) sequence of Strongyloides sp. determined herein (bold) and the selected reference sequences. A dot indicates an identical nucleotide with respect to the sequence of Strongyloides sp.; a dash indicates an insertion/deletion (indel) event.

\section{Acknowledgements}

The authors are thankful to the stud manager of the Thoroughbred farm in the Hunter Valley, New South Wales, Australia for providing faecal samples from foals.

The listed authors are members of the Australian Equine Parasite Advisory Panel supported by AgriFutures Australia and Boehringer Ingelheim Animal Health Australia.

\section{Authors' contributions}

GA and AJ conceived the idea and designed the study. GA processed the samples and performed lab experiments, AG and CG provided technical help during experiments. GA and AJ drafted the manuscript. AJ and AG contributed to the phylogenetic analysis. AK, AB, CJ, CEH, JB, EW, JH, LC, PC, BTB, KJH, MKN and IB commented on the structure of manuscript and provided critical intellectual input. All authors read and approved the final manuscript.

\section{Funding}

The financial assistance for this project was provided by the AgriFutures Australia, Thoroughbred Breeders Australia and Boehringer Ingelheim, Australia. GA is a grateful recipient of the Australian Government Research Training Scholarship through the University of Melbourne.

\section{Availability of data and materials}

All data generated or analysed during this study are included in this published article.

\section{Declarations}

Ethics approval and consent to participate

The collection of faecal samples from Australian Thoroughbred horses was approved by the Animal Ethics Committee of the University of Melbourne (Ethics ID: 1955146.1).

\section{Consent for publication}

Not applicable.

\section{Competing interests}

The authors declare that they have no competing interests.

\section{Author details}

${ }^{1}$ Melbourne Veterinary School, The University of Melbourne, Werribee, Australia. ${ }^{2}$ School of Animal and Veterinary Sciences, Charles Sturt University, 
Wagga Wagga, Australia. ${ }^{3}$ Centre for Animal Production and Health, Murdoch University, Murdoch, Australia. ${ }^{4}$ School of Agriculture and Food Science, University of Queensland, Gatton, Australia. ${ }^{5}$ Swettenham Stud, Nagambie, Australia. ${ }^{6}$ Scone Equine Hospital, Scone, Australia. ${ }^{7}$ M.H. Gluck Equine Research Center, Department of Veterinary Science, University of Kentucky, Lexington, KY, USA.

Received: 24 June 2021 Accepted: 18 August 2021

Published online: 03 September 2021

\section{References}

1. Speare R. Identification of species of Strongyloides. In: Grove DI, editor. Strongyloidiasis a major roundworm infection of man. London: Taylor and Francis; 1989. p. 11-84.

2. Lyons ET. Vertical transmission of nematodes: emphasis on Uncinaria lucasi in northern fur seals and Strongyloides westeri in equids. Proc Helminthol Soc Wash. 1994;61:169-78.

3. Lyons ET, Drudge JH, Tolliver SC. On the life cycle of Strongyloides westeri in the equine. J Parasitol. 1973;59:780-7.

4. Mirck MH. Strongyloides westeri Ihle, 1917 (Nematoda: Strongyloididae). I. Parasitological features of natural infection (author's transl). Tijdschr Diergeneeskd. 1977;102:1039-43.

5. Lyons ET, Tolliver SC. Review of some features of the biology of Strongyloides westeri with emphasis on the life cycle. Helminthologia. 2015;52:3-5.

6. Thamsborg SM, Ketzis J, Horii Y, Matthews JB. Strongyloides spp. infections of veterinary importance. Parasitology. 2017;144:274-84.

7. Dewes HF, Townsend KG. Further observations on Strongyloides westeri dermatitis: recovery of larvae from soil and bedding, and survival in treated sites. NZ Vet J. 1990:38:34-7.

8. Netherwood T, Wood JL, Townsend HG, Mumford JA, Chanter N. Foal diarrhoea between 1991 and 1994 in the United Kingdom associated with Clostridium perfringens, rotavirus, Strongyloides westeri and Cryptosporidium spp. Epidemiol Infect. 1996;117:375-83.

9. Lyons ET, Tolliver SC, Drudge JH, Granstrom DE, Collins SS. Natural infections of Strongyloides westeri: prevalence in horse foals on several farms in central Kentucky in 1992. Vet Parasitol. 1993;50:101-7.

10. Lyons ET, Tolliver SC. Strongyloides westeri and Parascaris equorum: observations in field studies in Thoroughbred foals on some farms in Central Kentucky, USA. Helminthologia. 2014;51:7-12.

11. Lyons ET, Tolliver SC. Prevalence of patent Strongyloides westeri infections in Thoroughbred foals in 2014. Parasitol Res. 2014;113:4163-4.

12. Miller FL, Bellaw JL, Lyons ET, Nielsen MK. Strongyloides westeri worm and egg counts in naturally infected young horses. Vet Parasitol. 2017;248:1-3.

13. Mfitilodze M, Hutchinson G. Prevalence and intensity of non-strongyle intestinal parasites of horses in northern Queensland. Aust Vet J. 1989;66:23-6.

14. Robertson GJ, Koehler AV, Gasser RB, Watts M, Norton R, Bradbury RS. Application of PCR-based tools to explore Strongyloides infection in people in parts of northern Australia. Trop Med Infect Dis. 2017;2:62.

15. Beknazarova M, Barratt JLN, Bradbury RS, Lane M, Whiley H, Ross K. Detection of classic and cryptic Strongyloides genotypes by deep amplicon sequencing: a preliminary survey of dog and human specimens collected from remote Australian communities. PLoS Negl Trop Dis. 2019;13:e0007241.
16. Ko PP, Sakaguchi K, Yoshida A, Maruyama H, Nonaka N, Nagayasu E. First molecular identification of Strongyloides vituli in cattle in Japan and insights into the evolutionary history of Strongyloides parasites of ruminants. Parasitol Int. 2019;72:101937.

17. Hasegawa H, Hayashida S, Ikeda Y, Sato H. Hyper-variable regions in $18 \mathrm{~S}$ rDNA of Strongyloides spp. as markers for species-specific diagnosis. Parasitol Res. 2009;104:869-74.

18. Anderson J, Upadhayay R, Sudimack D, Nair S, Leland M, Williams JT, et al. Trichuris sp. and Strongyloides sp. infections in a free-ranging baboon colony. J Parasitol. 2012;98:205-8.

19. Dorris M, Viney ME, Blaxter ML. Molecular phylogenetic analysis of the genus Strongyloides and related nematodes. Int J Parasitol. 2002;32:1507-17.

20. Gordon HM, Whitlock HV. A new technique for counting nematode eggs in sheep faeces. J Counc Sci Ind Res. 1939;12:50-2.

21. Roeber F, Jex AR, Gasser RB. Comparative evaluation of two DNA isolation techniques for PCR-based diagnosis of gastrointestinal nematode infections in sheep. Mol Cell Probes. 2013;27:153-7.

22. Darriba D, Taboada GL, Doallo R, Posada D. jModelTest 2: more models, new heuristics and parallel computing. Nat Methods. 2012;9:772

23. Kumar S, Stecher G, Li M, Knyaz C, Tamura K. MEGA X: molecular evolutionary genetics analysis across computing platforms. Mol Biol Evol. 2008;35:1547-9.

24. Huelsenbeck JP, Ronquist F. MRBAYES: Bayesian inference of phylogenetic trees. Bioinformatics. 2001;17:754-5.

25. Morris LH, Colgan S, Leathwick DM, Nielsen MK. Anthelmintic efficacy of single active and combination products against commonly occurring parasites in foals. Vet Parasitol. 2019;268:46-52.

26. Ljungström S, Melville L, Skuce PJ, Höglund J. Comparison of four diagnostic methods for detection and relative quantification of Haemonchus contortus eggs in feces samples. Front Vet Sci. 2018;4:239.

27. Roeber F, Larsen JWA, Anderson N, Campbell AJD, Anderson GA, Gasser $\mathrm{RB}$, et al. A molecular diagnostic tool to replace larval culture in conventional faecal egg count reduction testing in sheep. PLoS ONE. 2012; $7:$ e37327.

28. Eberhardt AG, Mayer WE, Bonfoh B, Streit A. The Strongyloides (Nematoda) of sheep and the predominant Strongyloides of cattle form at least two different, genetically isolated populations. Vet Parasitol. 2008;157:89-99.

29. Floyd R, Abebe E, Papert A, Blaxter M. Molecular barcodes for soil nematode identification. Mol Ecol. 2002;11:839-50.

30. Littlewood T. Reply-nucleotide sequences from vintage helminths: fine wine or vinegar? Parasitol Today. 1999;15:122.

31. Nagayasu E, Htwe MP, Hortiwakul T, Hino A, Tanaka T, Higashiarakawa M, et al. A possible origin population of pathogenic intestinal nematodes, Strongyloides stercoralis, unveiled by molecular phylogeny. Sci Rep. 2017;7:4844.

32. Viney ME, Ashford RW, Barnish G. A taxonomic study of Strongyloides grassi, 1879 (Nematoda) with special reference to Strongyloides fuelleborni von Linstow, 1905 in man in Papua New Guinea and the description of a new subspecies. Syst Parasitol. 1991;18:95-109.

\section{Publisher's Note}

Springer Nature remains neutral with regard to jurisdictional claims in published maps and institutional affiliations. 